\title{
Assessing Effect of Marker-Based Improvement of Maize Synthetics on Agronomic Performance, Carotenoid Content, Combining Ability and Heterosis
}

\author{
Innocent Iseghohi ${ }^{1,2,3, *}$, Ayodeji Abe ${ }^{2}$, Silvestro Meseka ${ }^{3}{ }^{\circ}$, Wende Mengesha ${ }^{3} \mathbb{C}^{\text {, }}$ \\ Melaku Gedil ${ }^{3}$ (D) and Abebe Menkir ${ }^{3, *}$ \\ 1 Department of Crop Science and Horticulture, Federal University Oye-Ekiti, \\ PMB 373, Oye-Ekiti 374101, Ekiti State, Nigeria \\ 2 Department of Agronomy, University of Ibadan, PMB 3017, Ibadan 200284, Oyo State, Nigeria; \\ ayodabe@yahoo.com \\ 3 International Institute of Tropical Agriculture (IITA), PMB 5320, Ibadan 200001, Oyo State, Nigeria; \\ S.Meseka@cgiar.org (S.M.); w.mengesha@cgiar.org (W.M.); m.gedil@cgiar.org (M.G.) \\ * Correspondences: innocent.iseghohi@fuoye.edu.ng (I.I.); A.Menkir@cgiar.org (A.M.)
}

Received: 28 August 2020; Accepted: 13 October 2020; Published: 22 October 2020

\begin{abstract}
Vitamin A deficiency (VAD) is a serious problem in sub-Saharan Africa (SSA) and other parts of the world. Understanding the effect of marker-based improvement (MARS) of two maize synthetics (HGA and HGB) representing different heterotic groups on their agronomic performance, carotenoid content, and combining abilities could help identify suitable sources to develop divergent inbred lines for optimizing heterosis. This study involved three selection cycles each of the two synthetics and their nine varietal-cross hybrids together with a released check variety was conducted across four diverse locations in Nigeria in 2018 and 2019. Environment and hybrid effects were significant on grain yield and other agronomic traits as well as provitamin A content and other carotenoids. Genetic improvement per cycle of MARS in the parental synthetics was $15 \%$ for provitamin A, $25 \%$ for $\beta$-carotene and $26 \%$ for lutein in HGA and $4 \%$ for grain yield, $3 \%$ for zeaxanthin and $5 \%$ for $\alpha$-carotene in HGB. Grain yield and agronomic traits of the two maize synthetics were controlled by additive and non-additive gene effects, while provitamin A content and other carotenoids were mainly controlled by additive gene effects. Some selection cycles which were high in grain yield and provitamin A content were identified as potential sources of new and divergent maize inbred lines in maize breeding programs. Some varietal-cross hybrids expressed significant mid-parent heterosis for grain yield and moderate mid-parent heterosis for provitamin A, $\beta$-carotene and xanthophylls. These hybrids could be commercialized at reasonable prices to small-scale farmers in rural areas that are most affected by vitamin A deficiency.
\end{abstract}

Keywords: combining ability; grain yield; heterosis; maize synthetics; provitamin A

\section{Introduction}

Maize is the second most widely grown cereal in the world next to wheat, with an estimated total production of over one billion tons per annum [1]. Maize and its products constitute $30 \%$ of the food supply in the Americas, 38\% in Africa and 6.5\% in Asia [2]. It is the most important staple crop widely consumed in sub-Saharan Africa (SSA) supplying daily energy, protein and mineral nutrients. Maize provides the highest percentage of calorie in the national diet of over 16 African countries [3]. Due to the prevalence and adverse effects of vitamin A deficiency in SSA, maize has been targeted as one of the food crops for Provitamin A (PVA) enrichment through plant breeding under the HarvestPlus challenge program $[4,5]$. 
Provitamin A carotenoids are precursors of vitamin A, which cannot be synthesized de novo in the human body but could be obtained from consumption of balanced diets and food supplements [6]. Yellow and orange maize naturally accumulate provitamin A carotenoids, including $\alpha$-carotene, $\beta$-carotene, and $\beta$-cryptoxanthin, which can be transformed into vitamin $A$ in the human body [7]. Lutein and zeaxanthin (xanthophylls) are also important carotenoids in maize endosperm, although they have no provitamin A activities [8]. Vitamin A is essential in regulating key biological processes in humans and its deficiency is associated with health disorders including night blindness, retarded growth, depressed immune response, poor lactation in breast-feeding mothers and high infant mortality $[9,10]$.

Significant breeding investments have been made to improve the provitamin A content in maize and other staple crops to combat vitamin A deficiency (VAD). The maize improvement program in the International Institute of Tropical Agriculture (IITA) in collaborations with its partners have over the years screened maize germplasm of tropical, subtropical and temperate backgrounds and developed inbred lines, hybrids and synthetics with favorable alleles for provitamin A carotenoids [11-14]. The rapid progress in molecular techniques and discovery of the genes Lycopene Epsilon Cylase, (LCYE) and $\beta$-carotene hydroxylase1 (crtRB1), which are key in provitamin A carotenoids accumulation, have led to significant improvement of provitamin A in different maize germplasm [15-18]. The carotenoid biosynthetic pathway has been well characterized and allelic variations in key genes have been exploited for DNA maker developments and validations $[17,19,20]$. These molecular markers are routinely deployed along with phenotypic quantification of carotenoids using such tool as high performance liquid chromatography (HPLC) to select high provitamin A maize lines [6].

Marker-assisted recurrent selection (MARS) is a breeding procedure that accumulates favorable alleles using molecular markers linked to target traits [21]. The utility of MARS in the improvement of grain yield, drought tolerance and resistance to Striga hermonthica in maize has been reported [22,23]. Ref. [24] reported a two-fold genetic gain through MARS in grain yield of some maize populations relative to phenotypic selection. Breeders at IITA developed two maize synthetics (HGA and HGB) representing two heterotic groups and subjected them independently to two cycles of marker-based selection to increase favorable alleles of provitamin A carotenoids. The effects of using such high throughput provitamin A markers on genetic improvement in grain yield and other traits have not been studied. [25] reported that the frequency of four favorable alleles of crtRB1 KASP markers as well as the fixation index increased in the two synthetics after the two cycles of MARS. These led to $40 \%$ increase in $\beta$-carotene and 30\% increase in provitamin A in HGA, but a 20\% increase in $\alpha$-carotene and a $5 \%$ increase in $\beta$-cryptoxanthin in HGB.

The development and marker-based improvement of HGA and HGB maize synthetics was designed to create source populations for extracting divergent parental lines with high provitamin A content and superior agronomic traits to develop provitamin A enriched hybrids. Understanding the effect of marker-based improvement of the two synthetics on their combining abilities for grain yield and other desirable agronomic traits as well as provitamin A carotenoids can provide useful information on the genetic control of these traits and facilitate the identification of suitable source populations for divergent parental lines with good general and specific combining abilities (GCA and SCA) to optimize expression of heterosis in hybrids. Few studies, mainly in maize inbred lines have reported combining ability for grain yield and provitamin A carotenoids [26-29]. However, the combining ability and heterosis for grain yield, agronomic traits and provitamin A carotenoids in maize synthetics improved using high throughput marker assisted recurrent selection has not been reported. Ref. [30] attributed the gene action controlling $\beta$-carotene, $\beta$-cryptoxanthin, lutein and zeaxanthin to additive effects while $[27,29]$ reported that both additive and non-additive gene effects control maize carotenoids. In contrast, ref. [31] reported the predominance of non-additive gene effects on all measured carotenoids in some tropical maize inbred lines. These conflicting reports in these studies highlight the need for further investigations into the mode of gene action controlling carotenoids in maize. 
Heterosis has been exploited for grain yield and agronomic traits in commercial maize hybrids [32]. However, heterosis for grain carotenoids is reported to be rare and infrequent in yellow and dent maize [33]. Significant SCA effects among genetically divergent parents are important for assessing the potential heterosis that can be attained in maize [32]. Consequently, ref. [27] proposed exploitation of heterotic groups to maximize heterosis for provitamin A content. This study was thus conducted to assess the effect of MARS on (i) agronomic performance and provitamin A carotenoids and (ii) combining ability and heterosis of grain yield and provitamin A carotenoids of the two maize synthetics.

\section{Materials and Methods}

\subsection{Genetic Materials and Field Evaluation}

Two maize synthetics belonging to different heterotic groups (HGA and HGB) and their advanced cycles were used in this study (Supplementary Table S1). The two maize synthetics were each developed from eight elite maize inbred lines with intermediate to high provitamin A content and were then independently subjected to two cycles of marker-assisted recurrent selection at IITA. Three gene specific markers ( $c r t R B 1-5^{\prime} T E, L y c E-3^{\prime}$ Indel, LycE-SNP-216) were initially used for cycle selection based on PCR and gel electrophoresis [20]. Subsequently, 7 KASP-SNP assays linked to $c r t R B 1$ gene, made available through CGIAR collaboration, were used for high throughput genotyping at Intertek for verification (Supplementary Table S2). A total of 167 KASP SNPs (14-23 per chromosome) were then used to assess genetic diversity and changes in allele frequencies caused by MARS after two cycles of selection [25] In the present study, cycle 0, 1 and 2 of HGA were crossed with cycle 0,1 and 2 of HGB using North Carolina Design II to generate nine varietal-cross hybrids. The three cycles each of the two synthetics, nine varietal-cross hybrids plus a released provitamin A enriched maize variety, PVASYN13 (Supplementary Table S1) were evaluated at four locations in Nigeria, namely Ikenne ( $3^{\circ} 42^{\prime} \mathrm{E}, 6^{\circ} 54^{\prime} \mathrm{N}, 30$ masl), Mokwa ( $5^{\circ} 4^{\prime} \mathrm{E}, 9^{\circ} 18^{\prime} \mathrm{N}, 457$ masl), Saminaka $\left(8^{\circ} 39^{\prime} \mathrm{E}, 10^{\circ} 34^{\prime} \mathrm{N}\right.$, 760 masl) and Zaria $\left(7^{\circ} 45^{\prime} \mathrm{E}, 11^{\circ} 8^{\prime} \mathrm{N}, 622\right.$ masl), during the 2018 and 2019 rainy seasons. The check variety (PVASYN13) was developed by IITA in collaboration with Institute of Agricultural Research (IAR) and released by National Agricultural Seeds Council of Nigeria (NASC) in 2017 as SAMMAZ 52 [34]. Study locations belong to different agroecological zones of Nigeria, receiving different amount of rainfall, temperature, solar radiation and relative humidity each year (Supplementary Table S3). The trial was arranged in a $4 \times 4$ incomplete block design with four replicates. Plots consisted four rows $5 \mathrm{~m}$ long with inter- and intra- row spacing of $0.75 \mathrm{~m}$ and $0.5 \mathrm{~m}$, respectively. The recommended fertilizer rate was applied and field management practices for optimum maize production were carried out at each test location [11,35]. Agronomic and yield data were recorded from the two middle rows while the two outer rows were self-pollinated for carotenoid analysis.

\subsection{Agronomic Data Collection}

Days to anthesis (DA) and days to silking (DS) were recorded as number of days from planting to when $50 \%$ of the plants in a plot shed pollen and had emerged silks, respectively. Anthesis-silking interval (ASI) was calculated as the difference between DS and DA. Plant height (PHT) and ear height (EHT) were measured in $\mathrm{cm}$ as the distance from the base of the plant to first tassel branch and the node bearing the upper ear, respectively. Plant aspect (PASP) was scored on a 1 to 5 scale; where 1 represented uniform, clean, vigorous and good overall phenotypic appeal, while 5 represented weak, diseased and poor overall phenotypic appeal [12]. Symptom severity of major foliar diseases (southern corn leaf rust, southern corn leaf blight and maize streak virus) were scored on a scale of 1 to 5 , where 1 represented slights leaf infection and 5 represented severe leaf infection. Husk cover was rated on a scale of 1 to 5 , where 1 represented tightly arranged husk tip and 5 represented loose and exposed husk tip. All ears in the two rows were harvested to determine grain yield per plot. Ear aspect (EASP) was scored on a 1 to 5 scale, where 1 represented clean, well filled, uniform and large ears, while 5 represented diseased, poorly filled, variable and small ears. Ears harvested were shelled and 
grain moisture content of shelled grains was measured using a portable Dickey-John moisture tester. The grain weight and moisture content were used to compute grain yield adjusted to $15 \%$ moisture.

\subsection{Carotenoid Analysis}

For each location and year, self-pollinated plants from each plot were harvested separately and a minimum of ten clean ears were selected, air-dried under ambient temperature, shelled and the grains bulked. Samples drawn from the bulk grain were analyzed for carotenoid content at the Food and Nutrition Laboratory of IITA using high-performance liquid chromatography (HPLC) machine (Water Corporation, Milford, MA, USA). The extraction followed a modified procedure described by [13,36]. Ten gram of grain sample was drawn for each entry in two replicates and ground using a knifetec 1095 small mill (FOSS, Eden Prairie, MN, USA). A 0.6 g ground sample was weighed and transferred into a $50 \mathrm{~mL}$ glass centrifuge tube. Six milliliters of ethanol containing $0.01 \%$ butyl hydroxyl toluene was added and mixed with vortex at 1000 revolution per minute (rpm) for $15 \mathrm{~s}$. Samples were then incubated in water bath at $85{ }^{\circ} \mathrm{C}$ for $5 \mathrm{~min}$. Samples were taken out of water bath and $0.5 \mathrm{~mL}$ of $80 \%$ potassium hydroxide was added and mixed with vortex at $1000 \mathrm{rpm}$ for $15 \mathrm{~s}$. Samples were placed in water bath at $85^{\circ} \mathrm{C}$ for $5 \mathrm{~min}$. Vortexing and incubation in water bath were repeated. Samples were immediately transferred into ice and $3 \mathrm{~mL}$ cold deionized water was added, capped and mixed with vortex for $15 \mathrm{~s}$. To each sample, $200 \mu \mathrm{L}$ of internal standard $\beta$-Apo $8^{\prime}$-carotenal and $3 \mathrm{~mL}$ of hexane was added, vortexed for $10 \mathrm{~s}$ and then centrifuged at $1000 \mathrm{rpm}$ for $10 \mathrm{~s}$. The upper phase of the solvent was pipetted into $50 \mathrm{~mL}$ concentrator tube for each sample. Extraction of the samples with $3 \mathrm{~mL}$ of hexane was repeated thrice. Extracts were dried under nitrogen gas at $40^{\circ} \mathrm{C}$ for $25 \mathrm{~min}$ using a concentrator (Organomation Associates, Inc., Berlin, MA, USA). Samples were then reconstituted in $1 \mathrm{~mL}$ of 50:50 dichloromethane/methanol and vortexed for $10 \mathrm{~s}$. Samples were transferred to HPLC vials, placed in auto-sampler tray and slid into the HPLC machine. For each sample, $50 \mu \mathrm{L}$ aliquots were injected into the HPLC system and run for major carotenoids based on the calibration of the standard of each carotenoid. Carotenoids were separated by $\mathrm{C}_{30}$ Column $(4.6 \times 250 \mathrm{~mm} ; 3 \mu \mathrm{m})$ eluted by a mobile phase using methanol/water (92: $8 \mathrm{v} / \mathrm{v})$ as solvent A and 100\% Methyl Tertiary Butyl Ether (MTBE) as solvent B. The flow rate of solvent was $1 \mathrm{~mL} /$ minute and absorbance was measured at $450 \mathrm{~nm}$ for carotenoid detection. Chromatograms (Supplementary Figure S1a,b) were extracted after the runs and major carotenoids were identified. Concentration of each carotenoid was calculated following the procedure of [37] as:

$$
\mathrm{C}_{\mathrm{X}}(\mathrm{ug} / \mathrm{g})=\frac{\mathrm{A}_{\mathrm{X}} \times \mathrm{C}_{\mathrm{S}}(\mathrm{ug} / \mathrm{mL}) \times \text { total volume of extact }(\mathrm{mL})}{\mathrm{A}_{\mathrm{s}} \times \text { sample weight }(\mathrm{g})}
$$

where $C_{X}$ and $A_{X}$ were concentration and peak area of carotenoid $X$, while $C_{s}$ and $A_{s}$ were the concentration and peak area of the standard. Total carotenoid was computed as the sum of concentrations of lutein, zeaxanthin, $\beta$-cryptoxanthin, $\alpha$-carotene and $\beta$-carotene (13-cis, trans and 9-cis isomers) while provitamin A content was calculated as the sum of $\beta$-carotene and half of $\beta$-cryptoxanthin and $\alpha$-carotene [38].

\subsection{Statistical Analyses}

Each location-year combination was considered an environment in the combined analysis of variance (ANOVA) using PROC MIXED procedure in SAS version 9.4 [39]. Entry was considered as fixed effect while environment, replication (environment), block (replication), environment $\times$ entry were regarded as random effects. The significances of entry and interaction effects were tested using the appropriate mean squares. Mean separations were done using Least Significant Difference (LSD) at 0.05 level of probability. For each trait, cycle means of parental synthetics were regressed on cycles of selection (C0-C2) using PROC REG in SAS 9.4 [39]. Genetic gain per cycle was calculated as the 
regression coefficient $(b)$ divided by the corresponding cycle zero (C0) mean [40]. Proportions of each carotenoid in the parents and varietal-cross hybrids were calculated as:

$$
\frac{\text { Mean of carotenoid }}{\text { mean of total carotenoid }} \times 100
$$

After the removal of the check variety from the entry list, analysis of variance based on North Carolina design II was carried out using a modification of DIALLEL-SAS program developed by [41]. Entries were considered as fixed effects, while environment and effects nested within it were regarded as random effects. Significant mean square of each main effect was tested using its respective interaction with the environment; whereas HGA $\times$ HGB $\times$ environment mean square was tested using the pooled error mean square. The GCA and SCA effects of the parental synthetics as well as the variance components for each trait were calculated with Analysis of Genetic Design (AGD-R, V.5.0) [42]. Variance components were based on Restricted Maximum Likelihood Method (REML) in AGD-R [42]. The significance of GCA and SCA effects were tested using t-statistic. The relative importance of GCA and SCA also known as predictability ratio was calculated following the procedure of [43] as:

$$
\frac{2 \sigma^{2} \mathrm{GCA}}{2 \sigma^{2} \mathrm{GCA}+\sigma^{2} \mathrm{SCA}}
$$

where, $\sigma^{2}$ GCA and $\sigma^{2}$ SCA were variances due to GCA and SCA, respectively. Repeatability values and narrow sense heritability for each trait were calculated in AGD-R [42] Mid-parent heterosis (MPH) was calculated according to [44] as:

$$
\mathrm{MPH}=\frac{\mathrm{F}_{1}-\mathrm{MP}}{\mathrm{MP}} \times 100
$$

Significance of heterosis was tested with t-statistic as:

$$
\operatorname{Tmp}=\frac{F_{1}-M P}{\sqrt{\frac{3 E M S}{2 r}}}
$$

where $F_{1}, M P$ were the means of crosses and mid-parents, respectively. Tmp was calculated $t$ of MP, while EMS was error mean square [32].

\section{Results}

\subsection{Variation among Maize Synthetics for Agronomic Traits and Carotenoids}

In the combined analysis, both environment and hybrid had significant effects on all measured agronomic traits (Table 1). The HGA cycles (GCA) was significant for grain yield and days to anthesis and silking, while HGB cycles (GCA) and SCA effects were significant for most or all agronomic traits. In contrast, the interactions of hybrids, HGA cycles (GCA), HGB cycles (GCA) and SCA with the environment were not significant, except for days to silking (Table 1). Significant effects of the environment and hybrid were also found for all or most carotenoids (Table 2). Although the effects of both HGA cycles (GCA) and HGB cycles (GCA) were significant for almost all the carotenoids, the SCA had no significant effects. Repeatability estimates for agronomic traits and carotenoids were generally high (Tables 1 and 2). Narrow-sense heritability estimates were moderate to high (0.50-0.82) for most agronomic traits and high (0.79-0.98) for all carotenoids except for $\alpha$-carotene which was zero (Table 2). 
Table 1. Mean squares from the analysis of variance of grain yield and agronomic traits of nine maize varietal-cross hybrids involving the various selection cycles of two synthetics evaluated across eight environments in Nigeria.

\begin{tabular}{|c|c|c|c|c|c|c|c|}
\hline Source & DF & Grain Yield & Days to Anthesis & Days to Silking & Anthesis-Silking Interval & Plant Aspect & Ear Aspect \\
\hline Env & 7 & $47.65^{* * *}$ & $369.35^{* * *}$ & $374.30 * * *$ & $3.27^{* * *}$ & $1.18^{* * *}$ & $1.46^{* * *}$ \\
\hline Rep (Env) & 24 & $1.38^{* * *}$ & $3.67^{* * *}$ & $4.15^{* * *}$ & 0.49 & $0.27^{*}$ & $0.32 * *$ \\
\hline Block $($ Env $\times$ Rep $)$ & 96 & 0.55 & 2.04 & $2.13 * *$ & 0.31 & 0.17 & 0.14 \\
\hline Hybrid & 8 & $10.71^{* * *}$ & $12.51^{* * *}$ & $15.00 * * *$ & $0.92 * *$ & $1.05^{* * *}$ & $1.45^{* * *}$ \\
\hline Env $\times$ Hybrid & 56 & 0.31 & 1.96 & $1.93 *$ & 0.28 & 0.15 & 0.12 \\
\hline HGA cycles (GCA) & 2 & $9.88^{* * *}$ & $13.66^{* *}$ & $8.94 * *$ & 0.66 & 0.04 & 0.10 \\
\hline HGB cycles (GCA) & 2 & $0.80 *$ & 11.01 ** & $23.48^{* *}$ & $2.33 * *$ & $0.86 *$ & $1.55^{* * *}$ \\
\hline SCA $(\mathrm{HGB} \times$ HGA $)$ & 4 & $14.62^{* * * *}$ & $14.50 * * *$ & $16.37^{* * *}$ & 0.30 & $1.67^{* * *}$ & $2.19^{* * *}$ \\
\hline Env $\times$ HGA cycles $($ GCA $)$ & 14 & 0.35 & 1.95 & 1.33 & 0.19 & 0.17 & 0.11 \\
\hline Env $\times$ HGB cycles $(G C A)$ & 14 & 0.21 & 1.59 & 2.19 * & 0.22 & 0.18 & 0.04 \\
\hline Env $\times$ SCA $($ HGB $\times$ HGA $)$ & 28 & 0.38 & 2.15 & $2.00 *$ & 0.37 & 0.11 & 0.16 \\
\hline Error & 96 & 0.49 & 1.47 & 1.21 & 0.46 & 0.16 & 0.14 \\
\hline Repeatability & & 0.99 & 0.99 & 0.99 & 0.82 & 0.98 & 0.99 \\
\hline Narrow-sense heritability & & 0.50 & 0.49 & 0.53 & 0.82 & 0.49 & 0.52 \\
\hline
\end{tabular}

$*, * * * * *$ : Significant at $0.05,0.01$ and 0.001 probability levels, respectively, DF: Degree of freedom.

Table 2. Mean squares from analysis of variance of provitamin A and other carotenoids of nine maize varietal-cross hybrids involving the various selection cycles of two synthetics evaluated across eight environments in Nigeria.

\begin{tabular}{|c|c|c|c|c|c|c|c|}
\hline Source & DF & Lutein & Zeaxanthin & $\beta$-Cryptoxanthin & $\alpha$-Carotene & $\beta$-Carotene & Provitamin A \\
\hline Env & 7 & $111.65^{* * *}$ & $28.01^{* * *}$ & $9.77^{* * *}$ & $1.50^{* * *}$ & $59.71^{* * *}$ & $96.06^{* * *}$ \\
\hline $\operatorname{Rep}(E n v)$ & 8 & $13.26^{* * *}$ & $4.99 *$ & 0.33 & 0.09 & 0.53 & 0.45 \\
\hline Hybrid & 8 & $44.28^{* * *}$ & $9.67^{* * *}$ & $0.80 * *$ & 0.04 & $11.54^{* * *}$ & $8.75^{* * *}$ \\
\hline Env $\times$ hybrid & 56 & 3.81 & 2.48 & 0.24 & 0.06 & 0.74 & 0.80 \\
\hline HGA cycles (GCA) & 2 & $57.15^{* * *}$ & $25.34^{* *}$ & $1.60 *$ & 0.02 & $22.71^{* * *}$ & $16.50 * * *$ \\
\hline HGB cycles (GCA) & 2 & $99.19^{* * *}$ & 6.95 & 1.04 * & 0.03 & $22.67^{* * *}$ & $17.74 * * *$ \\
\hline SCA $(\mathrm{HGB} \times \mathrm{HGA})$ & 4 & 10.39 & 3.20 & 0.29 & 0.05 & 0.39 & 0.39 \\
\hline Env $\times$ HGA cycles $($ GCA $)$ & 14 & 1.66 & 3.40 & 0.30 & 0.08 & 1.25 & 1.19 \\
\hline Env $\times$ HGB cycles $(G C A)$ & 14 & 4.20 & 2.04 & 0.18 & 0.07 & 0.85 & 1.10 \\
\hline $\mathrm{ENV} \times \mathrm{SCA}(\mathrm{HGB} \times \mathrm{HGA})$ & 28 & 4.70 & 2.24 & 0.24 & 0.04 & 0.43 & 0.46 \\
\hline Error & 64 & 2.87 & 2.22 & 0.17 & 0.06 & 0.70 & 0.81 \\
\hline Repeatability & & 0.98 & 0.93 & 0.91 & 0.00 & 0.98 & 0.98 \\
\hline Narrow-sense heritability & & 0.84 & 0.82 & 0.82 & 0.00 & 0.98 & 0.98 \\
\hline
\end{tabular}

$*{ }^{* *}, * * *$ : Significant at $0.05,0.01$ and 0.001 probability levels, respectively, DF: Degree of freedom. 


\subsection{Effect of MARS on Agronomic Performance and Carotenoid Content of Maize Synthetics}

Marker-assisted recurrent selection (MARS) had little effect on grain yield and agronomic traits of the maize synthetics in this study (Table 3). The three selection cycles of each maize synthetics produced significantly less grain yields than the released provitamin A enriched maize variety (PVASYN13). However, MARS increased provitamin A and $\beta$-carotene content in HGA but not in HGB (Table 4). The changes in provitamin $A$ and $\beta$-carotene content in HGA were associated with increase in lutein but decreases in zeaxanthin and $\beta$-cryptoxanthin. The changes in HGB with MARS did not follow any consistent trend for lutein, zeaxanthin and $\beta$-cryptoxanthin (Table 4).

Table 3. Mean performance and genetic gain per cycle of selection for grain yield and agronomic traits of two maize synthetics and selection cycles evaluated across eight environments in Nigeria.

\begin{tabular}{cccccc}
\hline ENTRY & $\begin{array}{c}\text { Grain Yield } \\
\text { (t/ha) }\end{array}$ & $\begin{array}{c}\text { Days to } \\
\text { Anthesis (d) }\end{array}$ & $\begin{array}{c}\text { Days to } \\
\text { Silking (d) }\end{array}$ & $\begin{array}{c}\text { Plant Aspect } \\
\mathbf{( 1 - 5 )}\end{array}$ & $\begin{array}{c}\text { Ear Aspect } \\
\mathbf{( 1 - 5 )}\end{array}$ \\
\hline PVASYNHGAC0 & 4.9 & 57.3 & 59.5 & 3.0 & 3.0 \\
PVASYNHGAC1 & 4.8 & 57.3 & 59.3 & 3.1 & 2.9 \\
PVASYNHGAC2 & 4.8 & 56.7 & 58.7 & 2.7 & 2.6 \\
PVASYNHGBC0 & 4.5 & 56.6 & 58.5 & 2.9 & 2.6 \\
PVASYNHGBC1 & 5.1 & 57.1 & 59.0 & 3.1 & 2.9 \\
PVASYNHGBC2 & 4.9 & 56.0 & 57.7 & 2.7 & 2.6 \\
PVASYN13(Check) & 5.5 & 56.6 & 58.7 & 2.8 & 2.4 \\
Mean & 4.9 & 56.8 & 58.8 & 2.9 & 2.7 \\
LSD (0.05) & 0.4 & 0.7 & 0.8 & 0.2 & 0.2 \\
Repeatability & 0.8 & 0.6 & 0.7 & 0.7 & 0.8 \\
CV (\%) & 15 & 2 & 3 & 14 & 14 \\
\% gain/cycle (HGA) & -1.6 & -0.5 & -0.7 & -5.0 & -6.3 \\
\% gain/cycle (HGB) & 4.0 & -0.6 & -0.6 & -2.2 & -1.0 \\
\hline
\end{tabular}

LSD: Least significant difference, CV: Coefficient of variation.

Table 4. Mean performance and genetic gain per cycle of selection for provitamin A and other carotenoids of two maize synthetics and selection cycles evaluated across eight environments in Nigeria.

\begin{tabular}{ccccccc}
\hline ENTRY & $\begin{array}{c}\text { Lutein } \\
(\mu \mathrm{g} / \mathrm{g})\end{array}$ & $\begin{array}{c}\text { Zeaxanthin } \\
(\mu \mathrm{g} / \mathrm{g})\end{array}$ & $\begin{array}{c}\boldsymbol{\beta} \text {-Cryptoxanthin } \\
(\mu \mathrm{g} / \mathrm{g})\end{array}$ & $\begin{array}{c}\boldsymbol{\alpha} \text {-Carotene } \\
(\mu \mathrm{g} / \mathrm{g})\end{array}$ & $\begin{array}{c}\boldsymbol{\beta} \text {-Carotene } \\
(\mu \mathrm{g} / \mathrm{g})\end{array}$ & $\begin{array}{c}\text { Provitamin } \\
\mathbf{A}(\mu \mathrm{g} / \mathrm{g})\end{array}$ \\
\hline PVASYNHGAC0 & 8.1 & 7.7 & 3.0 & 0.9 & 5.0 & 6.9 \\
PVASYNHGAC1 & 8.4 & 8.3 & 3.0 & 0.8 & 5.1 & 7.0 \\
PVASYNHGAC2 & 12.2 & 5.6 & 2.2 & 0.8 & 7.5 & 9.0 \\
PVASYNHGBC0 & 12.4 & 6.6 & 2.5 & 0.8 & 6.8 & 8.4 \\
PVASYNHGBC1 & 7.8 & 7.9 & 3.0 & 0.8 & 5.0 & 6.9 \\
PVASYNHGBC2 & 12.5 & 7.0 & 2.5 & 0.8 & 6.5 & 8.2 \\
PVASYN13(Check) & 7.0 & 11.7 & 4.3 & 1.2 & 5.8 & 8.6 \\
Mean & 9.8 & 7.8 & 2.9 & 0.9 & 6.0 & 7.9 \\
LSD (0.05) & 1.4 & 1.2 & 0.3 & 0.1 & 0.6 & 0.6 \\
Repeatability & 1.0 & 0.9 & 1.0 & 0.9 & 0.9 & 0.8 \\
CV (\%) & 20 & 22 & 16 & 21 & 15 & 10 \\
\% gain/cycle (HGA) & 26.0 & -13.5 & -13.0 & -6.3 & 25.0 & 15.0 \\
\% gain/cycle (HGB) & 1.0 & 3.0 & -0.2 & 5.0 & -2.0 & -1.4 \\
\hline
\end{tabular}

LSD: Least significant difference, CV: Coefficient of variation.

There was no significant difference among five varietal-cross hybrids in grain yield, but all produced significantly higher grain yields than the released provitamin A enriched maize variety, PVASYN13 (Table 5). These varietal-cross hybrids did not show marked differences in other agronomic traits except PVASYNHGBC0/PVASYNHGAC1 which significantly differed in ear aspect (Table 5). They were also found to be competitive with PVASYN13 in other agronomic traits. In the present study, lutein followed by provitamin A, zeaxanthin, $\beta$-carotene, $\beta$-cryptoxanthin and $\alpha$-carotene accounted for $28 \%, 22 \%, 22 \%, 17 \%, 8 \%$ and $3 \%$ of the total carotenoid (Supplementary Figure S2). 
Three varietal-cross hybrids did not differ significantly from PVASYN13 in their provitamin A content, with PVASYNHGBC0/PVASYNHGAC2 having $0.4 \mu \mathrm{g} / \mathrm{g}$ more provitamin A than PVASYN13 (Table 6). Crosses of PVASYNHGBC0 with PVASYNHGAC0, PVASYNHGAC1 and PVASYNHGAC2 had higher provitamin A and $\beta$-carotene content as opposed to other varietal-cross hybrids, except PVASYNHGBC2/PVASYNHGAC2. All varietal-cross hybrids with high provitamin A and $\beta$-carotene also had higher lutein content (Table 6).

Table 5. Mean performance for grain yield and agronomic traits of maize varietal-cross hybrids and check evaluated across eight environments in Nigeria.

\begin{tabular}{cccccc}
\hline ENTRY & $\begin{array}{c}\text { Grain Yield } \\
\text { (t/ha) }\end{array}$ & $\begin{array}{c}\text { Days to } \\
\text { Anthesis (d) }\end{array}$ & $\begin{array}{c}\text { Days to } \\
\text { Silking (d) }\end{array}$ & $\begin{array}{c}\text { Plant Aspect } \\
\mathbf{( 1 - 5 )}\end{array}$ & $\begin{array}{c}\text { Ear Aspect } \\
\mathbf{( 1 - 5 )}\end{array}$ \\
\hline PVASYNHGBC0/PVASYNHGAC0 & 6.2 & 55.0 & 56.7 & 2.6 & 2.3 \\
PVASYNHGBC1/PVASYNHGAC0 & 5.1 & 57.3 & 59.3 & 3.1 & 2.9 \\
PVASYNHGBC2/PVASYNHGAC0 & 6.4 & 55.5 & 57.3 & 2.6 & 2.2 \\
PVASYNHGBC0/PVASYNHGAC1 & 6.2 & 55.3 & 57.1 & 2.7 & 2.5 \\
PVASYNHGBC1/PVASYNHGAC1 & 5.3 & 56.2 & 58.2 & 3.0 & 2.7 \\
PVASYNHGBC2/PVASYNHGAC1 & 6.2 & 54.9 & 56.8 & 2.7 & 2.3 \\
PVASYNHGBC0/PVASYNHGAC2 & 4.6 & 56.7 & 58.3 & 2.9 & 2.6 \\
PVASYNHGBC1/PVASYNHGAC2 & 6.2 & 55.6 & 57.4 & 2.6 & 2.3 \\
PVASYNHGBC2/PVASYNHGAC2 & 5.0 & 56.2 & 57.9 & 2.8 & 2.5 \\
PVASYN13 (Check) & 5.5 & 56.6 & 58.7 & 2.8 & 2.4 \\
Mean & 5.6 & 55.9 & 57.8 & 2.8 & 2.5 \\
LSD (0.05) & 0.3 & 0.6 & 0.6 & 0.2 & 0.2 \\
CV (\%) & 12 & 2 & 2 & 15 & 15 \\
\hline
\end{tabular}

LSD: Least significant difference, CV: Coefficient of variation.

Table 6. Mean performance for provitamin A and other carotenoids of maize varietal-cross hybrids and check evaluated. across eight environments in Nigeria.

\begin{tabular}{|c|c|c|c|c|c|c|}
\hline ENTRY & $\begin{array}{l}\text { Lutein } \\
(\mu \mathrm{g} / \mathrm{g})\end{array}$ & $\begin{array}{l}\text { Zeaxanthin } \\
(\mu \mathrm{g} / \mathrm{g})\end{array}$ & $\begin{array}{c}\beta \text {-Cryptoxanthin } \\
(\mu \mathrm{g} / \mathrm{g})\end{array}$ & $\begin{array}{c}\alpha \text {-Carotene } \\
(\mu \mathrm{g} / \mathrm{g})\end{array}$ & $\begin{array}{c}\beta \text {-Carotene } \\
(\mu \mathrm{g} / \mathrm{g})\end{array}$ & $\begin{array}{c}\text { Provitamin } \\
\text { A }(\mu g / g)\end{array}$ \\
\hline PVASYNHGBC0/PVASYNHGAC0 & 10.3 & 7.1 & 2.8 & 0.8 & 6.2 & 8.0 \\
\hline PVASYNHGBC1/PVASYNHGAC0 & 7.9 & 8.4 & 3.0 & 0.8 & 4.6 & 6.6 \\
\hline PVASYNHGBC2/PVASYNHGAC0 & 10.6 & 8.1 & 3.0 & 0.9 & 5.5 & 7.4 \\
\hline PVASYNHGBC0/PVASYNHGAC1 & 10.1 & 7.8 & 2.9 & 0.9 & 6.0 & 7.9 \\
\hline PVASYNHGBC1/PVASYNHGAC1 & 9.2 & 7.9 & 3.0 & 0.9 & 5.0 & 6.9 \\
\hline PVASYNHGBC1/PVASYNHGAC2 & 9.1 & 7.0 & 2.9 & 0.9 & 5.8 & 7.7 \\
\hline PVASYNHGBC2/PVASYNHGAC2 & 13.2 & 6.5 & 2.5 & 0.8 & 6.8 & 8.4 \\
\hline PVASYN13 (Check) & 7.0 & 11.7 & 4.3 & 1.2 & 5.8 & 8.6 \\
\hline Mean & 10.0 & 7.8 & 2.9 & 0.9 & 5.9 & 7.8 \\
\hline LSD (0.05) & 1.2 & 1.2 & 0.3 & 0.2 & 0.6 & 0.6 \\
\hline CV $(\%)$ & 17 & 22 & 14 & 26 & 14 & 11 \\
\hline
\end{tabular}

LSD: Least significant difference, CV: Coefficient of variation.

\subsection{Effect of MARS on GCA and SCA Estimates for Grain Yield and Carotenoids}

The synthetic parent PVASYNHGAC0 and selection cycles PVASYNHGAC1 and PVASYNHGBC2 had significant and positive GCA effects for grain yield, whereas PVASYNHGAC2, PVASYNHGBC1 had significant and negative GCA effects for this trait (Table 7). PVASYNHGAC1 and PVASYNHGBC0 had significant and negative GCA effects for anthesis and silking days, whereas PVASYNHGAC2 and PVASYNHGBC1 had significant and positive GCA effects for these traits. PVASYNHGBC1 also had significant and positive GCA effects for plant aspect and ear aspect scores, which are undesirable. The only selection cycles with significant and positive GCA effects for provitamin A, $\beta$-carotene and lutein content were PVASYNHGAC2 and PVASYNHGBC0, while others had significant negative or no effects for these traits and other carotenoids. Also, PVASYNHGAC2 had significant and negative GCA 
effects for zeaxanthin and $\beta$-cryptoxanthin (Table 7). There was an inverse relationship between GCA effect for grain yield and GCA effect for provitamin A in HGA but not in HGB.

Table 7. General combining ability effects of maize synthetics for grain yield, agronomic traits, provitamin A and other carotenoids evaluated across eight environments in Nigeria.

\begin{tabular}{cccccc}
\hline \multicolumn{5}{c}{ Agronomic Traits } \\
\hline Parent & Grain Yield & Days to Anthesis & Days to Silking & Plant Aspect & Ear Aspect \\
\hline PVASYNHGAC0 & $0.17^{* *}$ & 0.13 & 0.16 & -0.02 & $0.04^{*}$ \\
PVASYNHGAC1 & $0.30^{* * *}$ & $-0.55^{* * *}$ & $-0.46^{* *}$ & -0.01 & 0.00 \\
PVASYNHGAC2 & $-0.47^{* * *}$ & $0.42^{* *}$ & $0.30^{*}$ & 0.03 & $-0.04^{*}$ \\
PVASYNHGBC0 & 0.04 & $-0.34^{*}$ & $-0.50^{* *}$ & $-0.09^{*}$ & -0.03 \\
PVASYNHGBC1 & $-0.14^{* *}$ & $0.51^{* * *}$ & $0.75^{* * *}$ & $0.14^{* * *}$ & $0.19^{* * *}$ \\
PVASYNHGBC2 & $0.10^{* *}$ & -0.17 & -0.25 & -0.05 & $-0.16^{* * *}$ \\
SED (0.05) & 0.05 & 0.13 & 0.15 & 0.04 & 0.02 \\
$\sigma^{2}$ GCA & 0.45 & 0.57 & 0.65 & 0.04 & 0.05 \\
\hline & & \multicolumn{3}{c}{} \\
\hline Parent & Lutein & Zeaxanthin & $\beta$-cryptoxanthin & $\beta-$ carotene & Provitamin A \\
\hline PVASYNHGAC0 & $-0.99^{* * *}$ & 0.36 & 0.09 & $-0.26^{*}$ & $-0.23^{*}$ \\
PVASYNHGAC1 & -0.10 & $0.43^{*}$ & 0.09 & $-0.44^{* * *}$ & $-0.40^{* * *}$ \\
PVASYNHGAC2 & $1.09^{* * *}$ & $-0.79^{* * *}$ & $-0.18^{* * *}$ & $0.70^{* * *}$ & $0.62^{* * *}$ \\
PVASYNHGBC0 & $1.27^{* * *}$ & -0.12 & -0.05 & $0.62^{* * *}$ & $0.60^{* * *}$ \\
PVASYNHGBC1 & $-1.97^{* * *}$ & 0.32 & $0.17^{* *}$ & $-0.63^{* * *}$ & $-0.54^{* * *}$ \\
PVASYNHGBC2 & $0.70^{* *}$ & -0.20 & $-0.12^{*}$ & 0.01 & -0.06 \\
SED (0.05) & 0.25 & 0.19 & 0.05 & 0.10 & 0.11 \\
$\sigma^{2}$ GCA & 2.53 & 0.45 & 0.04 & 1.56 & 0.70 \\
\hline$* * * * * *$ Significant at $0.05,0.01$ and 0.001 probability levels, respectively, SED: Standard error of difference, $\sigma^{2}$ GCA: \\
Genetic variance due to general combining ability. & & &
\end{tabular}

Amongst the nine varietal cross hybrids, four (PVASYNHGBC0/PVASYNHGAC0, PVASYNHGBC2/ PVASYNHGAC0, PVASYNHGBC2/PVASYNHGAC1 and PVASYNHGBC1/PVASYNHGAC2) combined significant and positive SCA effects for grain yield with desirable SCA effects in other agronomic traits (Table 8). Almost all the carotenoids including provitamin A had no significant SCA effects in the present study. Predictability ratio which shows the relative importance of GCA over SCA in the inheritance of each trait in the hybrids was moderate for grain yield and other agronomic traits and high for provitamin A and other carotenoids (Table 8).

\subsection{Effect of MARS on Heterosis Estimates}

Five varietal-cross hybrids had significant mid-parent heterosis (MPH) for grain yield, while three other hybrids had non-significant MPH for the trait (Table 9). Although MPH for all carotenoids including provitamin A was not significant, however, PVASYNHGBC0/PVASYNHGAC0, PVASYNHGBC0/PVASYNHGAC1 and PVASYNHGBC0/PVASYNHGAC2 had positive MPH for provitamin A. Two of these varietal-cross hybrids PVASYNHGBC0/PVASYNHGAC0 and PVASYNHGBC0/PVASYNHGAC1 combined significant positive mid-parent heterosis for grain yield with positive MPH for provitamin A content (Table 9). 
Table 8. Specific combining ability effects of maize synthetics for grain yield, agronomic traits, provitamin A and other carotenoids evaluated across eight environments in Nigeria.

\begin{tabular}{|c|c|c|c|c|c|}
\hline Hybrid & Grain Yield & Days to Anthesis & Days to Silking & Plant Aspect & Ear Aspect \\
\hline PVASYNHGBC0/PVASYNHGAC0 & $0.32 * *$ & $-0.71^{* *}$ & $-0.68^{* *}$ & -0.07 & -0.12 \\
\hline PVASYNHGBC1/PVASYNHGAC0 & $-0.58^{* * *}$ & $0.68 *$ & $0.73^{* *}$ & $0.24^{* * *}$ & $0.29^{* * *}$ \\
\hline PVASYNHGBC2/PVASYNHGAC0 & 0.26 * & 0.03 & -0.06 & $-0.17^{* *}$ & $-0.17^{*}$ \\
\hline PVASYNHGBC0/PVASYNHGAC1 & 0.20 & -0.10 & -0.08 & -0.05 & -0.03 \\
\hline PVASYNHGBC1/PVASYNHGAC1 & $-0.51^{* * *}$ & 0.27 & 0.33 & $0.12 *$ & 0.12 \\
\hline PVASYNHGBC2/PVASYNHGAC1 & $0.31^{* *}$ & -0.17 & -0.25 & -0.07 & -0.09 \\
\hline PVASYNHGBC0/PVASYNHGAC2 & $-0.52 * * *$ & $0.81^{* *}$ & $0.75^{* *}$ & $0.12 *$ & $0.15^{*}$ \\
\hline PVASYNHGBC1/PVASYNHGAC2 & $1.09 * * *$ & $-0.95^{* * *}$ & $-1.06^{* * *}$ & $-0.36^{* * *}$ & $-0.41^{* * *}$ \\
\hline PVASYNHGBC2/PVASYNHGAC2 & $-0.57 * * *$ & 0.14 & 0.31 & $0.24^{* * *}$ & $0.26^{* * *}$ \\
\hline $\operatorname{SED}(0.05)$ & 0.11 & 0.26 & 0.25 & 0.06 & 0.07 \\
\hline$\sigma^{2} \mathrm{SCA}$ & 0.45 & 0.57 & 0.56 & 0.04 & 0.05 \\
\hline Predictability ratio & 0.67 & 0.67 & 0.70 & 0.67 & 0.67 \\
\hline Hybrid & Lutein & Zeaxanthin & $\beta$-cryptoxanthin & $\beta$-carotene & Provitamin A \\
\hline PVASYNHGBC0/PVASYNHGAC0 & 0.86 & -0.13 & -0.07 & 0.03 & 0.00 \\
\hline PVASYNHGBC1/PVASYNHGAC0 & -0.37 & -0.05 & -0.10 & -0.03 & -0.10 \\
\hline PVASYNHGBC2/PVASYNHGAC0 & -0.48 & 0.18 & 0.17 & 0.01 & 0.11 \\
\hline PVASYNHGBC0/PVASYNHGAC1 & $-1.06^{*}$ & 0.28 & 0.19 & -0.16 & -0.04 \\
\hline PVASYNHGBC1/PVASYNHGAC1 & $1.04^{*}$ & -0.09 & -0.08 & 0.27 & 0.21 \\
\hline PVASYNHGBC2/PVASYNHGAC1 & 0.02 & -0.19 & -0.10 & -0.11 & -0.17 \\
\hline PVASYNHGBC0/PVASYNHGAC2 & 0.20 & -0.15 & -0.12 & 0.14 & 0.04 \\
\hline PVASYNHGBC1/PVASYNHGAC2 & -0.66 & 0.15 & 0.18 & -0.24 & -0.10 \\
\hline PVASYNHGBC2/PVASYNHGAC2 & 0.46 & 0.01 & -0.06 & 0.10 & 0.06 \\
\hline $\operatorname{SED}(0.05)$ & 0.43 & 0.33 & 0.10 & 0.20 & 0.20 \\
\hline$\sigma^{2} \mathrm{SCA}$ & 0.42 & 0.06 & 0.01 & 0.00 & 0.00 \\
\hline Predictability ratio & 0.92 & 0.94 & 0.94 & 1.00 & 1.00 \\
\hline
\end{tabular}

$*, * * * * *$ Significant at $0.05,0.01$ and 0.001 probability levels, respectively, SED: Standard error of difference, $\sigma^{2} \mathrm{GCA}$ : Genetic variance due to general combining ability. 
Table 9. Percentage Mid-parent heterosis for grain yield, provitamin A and other carotenoids of varietal-cross hybrids. evaluated across eight environments in Nigeria.

\begin{tabular}{|c|c|c|c|c|c|c|c|}
\hline Hybrid & Grain Yield & Lutein & Zeaxanthin & $\beta$-Cryptoxanthin & $\alpha$-Carotene & $\beta$-Carotene & Provitamin A \\
\hline PVASYNHGBC0/PVASYNHGAC0 & $30.2^{* * *}$ & 1.0 & 0.0 & 0.9 & 0.6 & 4.8 & 4.0 \\
\hline PVASYNHGBC1/PVASYNHGAC0 & 1.3 & -0.7 & 8.2 & 0.8 & 1.2 & -7.4 & -5.1 \\
\hline PVASYNHGBC2/PVASYNHGAC0 & $31.0^{* * *}$ & 3.1 & 10.8 & 7.7 & 8.1 & -4.9 & -1.9 \\
\hline PVASYNHGBC0/PVASYNHGAC1 & $32.6^{* * *}$ & -2.5 & 5.0 & 6.2 & 6.9 & 1.1 & 2.3 \\
\hline PVASYNHGBC1/PVASYNHGAC1 & 6.9 & 13.7 & -2.2 & 0.7 & 13.9 & -1.6 & -0.1 \\
\hline PVASYNHGBC2/PVASYNHGAC1 & $27.9 * *$ & -0.7 & -7.3 & -0.5 & -2.4 & -6.2 & -5.0 \\
\hline PVASYNHGBC0/PVASYNHGAC2 & -1.8 & 2.6 & 0.5 & 2.1 & 2.6 & 2.7 & 2.6 \\
\hline PVASYNHGBC1/PVASYNHGAC2 & 25.6 ** & -9.5 & 2.9 & 11.2 & 16.3 & -6.7 & -2.8 \\
\hline PVASYNHGBC2/PVASYNHGAC2 & 3.0 & 6.4 & 2.9 & 4.5 & -0.6 & -3.6 & -2.3 \\
\hline $\operatorname{SED}(0.05)$ & 0.4 & 1.5 & 1.3 & 0.4 & 0.2 & 0.7 & 0.8 \\
\hline
\end{tabular}

**,***: Significant at 0.01 and 0.001 probability levels, respectively, SED: Standard error of difference. 


\section{Discussion}

This study was carried out to examine the effect of MARS on agronomic performance, carotenoid content, combining ability and heterosis of maize synthetics, which were improved with selection for provitamin A through high throughput markers. Results showed that environmental differences significantly induced genotypic variations in grain yield, agronomic traits and provitamin A accumulation, possibly due to differences in climatic and edaphic factors in the different environments [12]. The non-significant genotype $\times$ environment interaction for grain yield indicated that the synthetics and their cross hybrids were stable across test environments, suggesting that they have broad adaptation to diverse field environments [45]. In addition, the non-crossover genotype $\times$ environment interaction for provitamin $A$ and $\beta$-carotene indicate that the synthetics had consistent ranks in the different environments, consistent with the findings in other studies $[11,27,30]$.

MARS was effective in improving provitamin A, $\beta$-carotene and lutein content in HGA. However, MARS decreased zeaxanthin, $\beta$-cryptoxanthin and $\alpha$-carotene in HGA and Provitamin A, $\beta$-carotene and $\beta$-cryptoxanthin in HGB, suggesting that MARS increased favorable alleles of $c r t R B 1$ and LCYE more in HGA than in HGB, consistent with the earlier report of [25]. As grain yield and other agronomic traits were not targeted during the improvement of the two maize synthetics using MARS, there was no apparent improvement in grain yield in HGA but there was a $4 \%$ increase in grain yield per cycle in HGB, signifying the needs for further improvements of these traits in the two maize synthetics. Genetic gain in grain yield in HGB was lower than the results obtained by [46]but higher than the gains in two open-pollinated maize cultivars studied by [14]. It is difficult to compare the genetic gain in provitamin A obtained in this study with those of other studies as there are no reports of maize improved for provitamin A through high throughput provitamin A markers. However, the result is consistent with the findings of [14]who used $S_{1}$ selection method to improve provitamin $A$ and other carotenoids in open-pollinated maize cultivars. The increase in provitamin A content with either improvement or little change in grain yield in the present study, was contrary to the results reported in other studies indicating undesirable association between the two traits $[14,47,48]$. Consequently, simultaneous improvements in grain yield and provitamin A can be made through combined use of marker-based and phenotypic selections to develop desirable source populations.

The observed significant GCA and SCA effects for grain yield and other agronomic traits in our study indicated the importance of both additive and non-additive gene effects in the inheritance of these traits [32]. Conversely, the significant GCA but non-significant SCA effects for provitamin A and most carotenoids indicated the predominance of additive gene effects in their inheritance, consistent with the results reported in other studies involving maize inbred lines $[26,28,30,49,50]$. This, however, contradicts with the results of $[27,29]$ who reported the presence of additive and non-additive gene effects in the inheritance of Provitamin A while [31] reported the preponderance of non-additive gene effects in the inheritance of provitamin A and other carotenoids. In spite of the conflicting reports obtained in studies involving maize inbred lines with different genetic backgrounds, our study had provided additional information on the mode of gene action controlling the inheritance of provitamin A and carotenoids in maize synthetics.

The presence of additive and non-additive gene effects for grain yield and agronomic traits in the current study suggests that the maize synthetics could further be improved through recurrent selection to increase the frequency of favourable alleles [27,51]. Both additive and non-additive gene effects are important for exploitation of heterosis in hybrid development [52]. The cycles of selection of HGA and HGB with significant positive GCA effects for both grain yield and provitamin A carotenoids could be selected as potential testers to detect differences among testcrosses of new maize inbred lines in provitamin A content and agronomic performance. Such selection cycles of the two synthetics can also be targeted for further improvement using reciprocal recurrent selection to develop source populations for divergent maize inbred lines that optimize expression of heterosis in both grain yield and provitamin A content. Furthermore, the predominance of GCA over SCA effects highlights the potential that exists for effective evaluation of early generation lines to identify promising hybrids for 
further testing [51]. The preponderance of additive gene effect for Provitamin A and other carotenoids indicated that the favorable alleles of CrtRB1 and LCYE could be accumulated for enhanced provitamin A content in varietal-cross hybrids [50]. The varietal-cross hybrids PVASYNHGBC0/PVASYNHGAC0 and PVASYNHGBC2/PVASYNHGAC0 which had positive SCA effects for grain yield and provitamin A could be improved further using reciprocal recurrent selection to develop new and divergent maize inbred lines for optimizing heterosis in hybrids.

The observed significant MPH for grain yield in most of the varietal-cross hybrids could be attributed to the presence of additive and non-additive gene effects arising from significant GCA and SCA effects. Conversely, the low and non-significant MPH observed for provitamin A and other carotenoids could be due to the non-significant SCA effects for maize carotenoids. Hybrid vigor in maize is manifested in the offspring of inbred lines with high SCA effects [32]. Therefore, the lack of significant SCA effects for provitamin A and $\beta$-carotene is an evidence of lack of dominance effects of favorable alleles in the maize hybrids. [53] stated that, to achieve significant heterosis for provitamin $\mathrm{A}$ in maize, non-additive gene effect is required. However, the positive heterosis for provitamin $\mathrm{A}$ and $\beta$-carotene observed in crosses involving PVASYNHGBC0 could be due to its significant GCA effects. It thus appears that PVASYNHGBC0 carried favorable alleles that could result in heterosis when crossed with other genotypes with high provitamin A contents. The relatively low level of heterosis for provitamin A and other carotenoids recorded in most of the varietal cross hybrids in the current study is consistent with the results of [33] who reported that heterosis for provitamin A carotenoids is rare and infrequent in yellow or dent maize. Although the genetic basis of heterosis is yet to be unraveled [54], [33] attributed heterosis for maize carotenoids to being influenced by QTLs' affecting the total flux through the carotenoid biosynthesis pathway as well as QTLs that favor flux to one branch of the pathway over the other branch. Based on the results of the current study, continuous selection for favorable alleles of $\beta$-carotene, $\beta$-cryptoxanthin of the $\beta$-branch of the pathway with corresponding reduction of flux into the $\alpha$-branch could further increase heterosis of provitamin $\mathrm{A}$ in the maize varietal-cross hybrids $[2,8,55]$.

The five varietal-cross hybrids which had significant MPH for grain yield produced significantly higher yields in comparison to the released provitamin A enriched maize variety (PVASYN13). In addition, two of the varietal-cross hybrids had positive MPH for grain yield, provitamin A and $\beta$-carotene content. This demonstrates the genetic potentials of the varietal-cross hybrids for grain yield and provitamin A. Xanthophylls (Lutein and Zeaxanthin) constituted 50\% of the total carotenoids in this study, consistent with carotenoid profiles of commonly reported in tropical maize germplasm $[12,27,31,33]$. The relative proportions of provitamin A $(22 \%), \beta$-carotene $(17 \%)$, $\beta$-cryptoxanthin (8\%) and $\alpha$-carotene (3\%) obtained in kernels of the genotypes included in this study were higher than the corresponding values commonly reported for yellow maize by the USDA National Nutrient Database (ndb.nal.usda.gov). In addition, previous authors [11,12,15,17,26-29,31,56] had reported lower levels of provitamin A, $\beta$-carotene and lutein than obtained in this study. This implied that the maize synthetics and their varietal-cross hybrids in our study contained appreciable levels of provitamin A carotenoids and xanthophylls that could be deployed in breeding programs to combat vitamin A deficiency and other related diseases in SSA.

\section{Conclusions}

Marker-assisted recurrent selection was effective in improving provitamin A, $\beta$-carotene and lutein in HGA and zeaxanthin and $\alpha$-carotene in HGB. The study demonstrated that grain yield and agronomic traits of maize synthetics were controlled by additive and non-additive gene effects, while provitamin A and associated carotenoids were predominantly controlled by additive gene effects. This was important in identifying parents that could be sources of inbred lines combining high grain yield with high provitamin A content in maize breeding programs. Some varietal-cross hybrids had significant mid-parent heterosis for grain yield and moderate mid-parent heterosis for provitamin A, $\beta$-carotene and xanthophylls. The synthetic parent PVASYNHGBC0 and varietal-cross hybrids 
PVASYNHGBC0/PVASYNHGAC0 and PVASYNHGBC2/PVASYNHGAC0 which combined well for both grain yield and provitamin A content could be advanced in breeding programs for inbred line development. Other parents such as PVASYNHGAC0, PVASYNHGAC1 and PVASYNHGBC2 which combined well for grain yield and agronomic traits, and PVASYNHGAC2 which combined well for provitamin A content could further be improved to develop source populations for divergent maize inbred lines.

Supplementary Materials: The following are available online at http://www.mdpi.com/2073-4395/10/11/1625/s1, Table S1: Two provitamin A maize synthetics, their selection cycles, varietal-cross hybrids and a check variety included in the present study, Table S2: crtRB1 Kompetitive Allele Specific PCR (KASP) assays used to improve provitamin A carotenoids in two maize synthetics (HGA and HGB) evaluated across eight environment in Nigeria, Table S3: Agroecological zones, average rainfall, temperature, relative humidity and soil type of the study locations, Figure S1a,b: Chromatograms of carotenoids of selection cycles of maize synthetics and varietal-cross hybrids quantified using high performance liquid chromatography (HPLC) at the International Institute of Tropical Agriculture (IITA), Ibadan, Nigeria. Peaks are (1) lutein (2) zeaxanthin (3) $\beta$-cryptoxanthin (4) $\alpha$-carotene (5) 13-cis $\beta$-carotene (6) trans $\beta$-carotene (7) 9-cis $\beta$-carotene, Figure S2: Proportions of carotenoids measured in maize parental synthetics, varietal-cross hybrids and a check evaluated across eight environments in Nigeria.

Author Contributions: Conceptualization, A.M., A.A. and I.I.; Methodology, I.I., A.M., A.A. and S.M.; Data curation, I.I. and A.M.; Formal analysis, I.I.; Writing—original draft preparation, I.I.; Writing-review and editing, I.I., A.M., A.A., S.M., W.M. and M.G.; Supervision, A.A., A.M., S.M. and W.M.; Project administration, A.M.; Funding acquisition, A.M. and I.I. All authors have read and agreed to the published version of the manuscript.

Funding: The first author received financial support from the Tertiary Education Trust Fund (TETFUND) through the Academic Staff Training Development (ASTD) awarded to Federal University Oye-Ekiti, Ekiti State, Nigeria for the Ph.D. program. This research was funded by The Bill and Melinda Gates Fundation (BMGF Chronos) grant number OPP1019962. The authors appreciate the financial support from the HarvestPlus Challenge Program for conducting trials in different locations and running carotenoid analyses of samples.

Acknowledgments: The work is part of Ph.D. research of the first author. The authors wish to thank the staff of Maize Improvement Program (MIP) and Food and Nutrition Laboratory of the International Institute of Tropical Agriculture (IITA) for their technical supports.

Conflicts of Interest: The authors declare no conflict of interest.

\section{References}

1. FAOSTAT. 2018. Available online: http://www.fao.org/faostat/en/\#data/QC (accessed on 8 June 2020).

2. Prasanna, B.M.; Palacios-Rojas, N.; Hossain, F.; Muthusamy, V.H.; Menkir, A.; Dhliwayo, T.; Ndhlela, T.; Vicente, F.S.; Nair, S.K.; Vivek, B.S.; et al. Molecular breeding for nutritionally enriched maize: Status and prospects. Front. Genet. 2020, 10, 1392. [CrossRef] [PubMed]

3. Nuss, E.T.; Tanumihardjo, S.A. Quality protein maize for Africa: Closing the protein inadequacy gap in vulnerable populations. Adv. Nutr. 2011, 2, 217-224. [CrossRef] [PubMed]

4. Pfeiffer, W.H.; McClafferty, B. Biofortification: Breeding micronutrient-dense crops. In Breeding Major Food Staples; Kang, M.S., Priyadarshan, P.M., Eds.; Blackwell Publishing: Hoboken, NJ, USA, 2007; pp. 61-91.

5. Bouis, H.E.; Welch, R.M. Biofortification-A sustainable agricultural strategy for reducing micronutrient malnutrition in the Global South. Crop Sci. 2010, 50, 20-32. [CrossRef]

6. Gupta, H.S.; Hossain, F.; Muthusamy, V.; Zunjare, R.U. Marker-Assisted Breeding for enrichment of provitamin A in maize. In Quality Breeding in Field Crops; Qureshi, A.M.I., Dar, Z.A., Wani, S.H., Eds.; Springer Nature: Basel, Switzerland, 2019. [CrossRef]

7. Asson-Batres, M.A.; Rochette-Egly, C. The Biochemistry of Retinoid Signaling II: The Physiology of Vitamin A-Uptake, Transport, Metabolism and Signaling; Springer Nature: Dordrecht, The Netherlands, 2016. [CrossRef]

8. Wurtzel, E.T.; Cuttriss, A.; Vallabhaneni, R. Maize provitamin A carotenoids, current resources, and future metabolic engineering challenges. Front. Plant Sci. 2012, 3, 1-12. [CrossRef] [PubMed]

9. Rice, A.L.; West, K.P., Jr.; Black, R.E. Vitamin A deficiency. Comparative Quantification of Health Risks—Global and Regional Burden of Disease Attributed to Selected Major Risk Factors; Ezzati, M., Lopez, A.D., Rodgers, A., Murray, C.J.L., Eds.; The World Health Organization: Geneva, Switzerland, 2004; Volume 1.

10. Muthayya, S.; Hyu Rah, J.; Sugimoto, J.; Roos, F.; Kraemer, K.; Black, R. The global hidden hunger indices and maps: An advocacy tool for action. PLoS ONE 2013, 8, e67860. [CrossRef] 
11. Menkir, A.; Liu, W.; White, W.S.; Maziya-Dixon, B.; Rocheford, T. Carotenoid diversity in tropical-adapted yellow maize inbred lines. Food Chem. 2008, 109, 521-529. [CrossRef]

12. Menkir, A.; Gedil, M.; Tanumihardjo, S.; Adepoju, A.; Bossey, B. Carotenoid accumulation and agronomic performance of maize hybrids involving parental combinations from different marker-based groups. Food Chem. 2014, 148, 131-137. [CrossRef]

13. Menkir, A.; Rocherford, T.; Maziya-Dixon, B.; Tanumihardjo, S. Exploiting natural variation in exotic germplasm for increasing provitamin-A carotenoids in tropical maize. Euphytica 2015, 205, 203-217. [CrossRef]

14. Dhliwayo, T.; Palacios-Roja, N.; Crossa, J.; Pixley, V. Effects of $S_{1}$ Recurrent selection for provitamin A carotenoid content for three open-pollinated maize cultivars. Crop Sci. 2014, 54, 2449-2460. [CrossRef]

15. Harjes, C.E.; Rocheford, T.R.; Bai, L.; Brutnell, T.P.; Vallabhaneni, R.; Williams, M.; Wurtzel, E.T.; Kandianis, C.B.; Sowinski, S.G.; Stapleton, A.E.; et al. Natural genetic variation in lycopene epsilon cyclase tapped for maize biofortification. Science 2008, 319, 330-333. [CrossRef]

16. Yan, J.; Kandianis, C.B.; Harjes, C.E.; Bai, L.; Kim, E.-H.; Yang, X.; Skinner, D.J.; Fu, Z.; Mitchell, S.; Li, Q.; et al. Rare genetic variation at Zea mays crtRB1 increases b-carotene in maize grain. Nat. Genet. 2010, 42, 322-329. [CrossRef] [PubMed]

17. Azmach, G.; Gedil, M.; Menkir, A.; Spillane, C. Marker-trait association analysis of functional gene markers for provitamin A levels across diverse tropical yellow maize inbred lines. Biomed. Cent. Plant Biol. 2013, 13, 227-243. [CrossRef] [PubMed]

18. Gedil, M.; Menkir, A. An integration molecular and conventional breeding scheme for enhancing genetic gain in maize in Africa. Front. Plant Sci. 2019, 10, 1-17. [CrossRef] [PubMed]

19. Babu, R.; Rojas, N.P.; Gao, S.; Yan, J.; Pixley, K. Validation of the effects of molecular marker polymorphisms in LCYE and CrtRB1 on provitamin A concentrations for 26 tropical maize populations. Theor. Appl. Genet. 2013, 126, 389-399. [CrossRef]

20. Gebremeskel, S.; Garcia-Oliveira, A.L.; Menkir, A.; Adetimirin, V.; Gedil, M. Effectiveness of predictive markers for marker assisted selection of pro-vitamin A carotenoids in medium-late maturing maize (Zea mays L.) inbred lines. J. Cereal Sci. 2018, 79, 27-34. [CrossRef]

21. Bernardo, R. Molecular markers and selection for complex traits in plants: Learning from the last 20 years. Crop Sci. 2008, 48, 1649-1664. [CrossRef]

22. Abdulmalik, R.O.; Menkir, A.; Meseka, S.; Unachukwu, N.; Ado, S.G.; Olarewaju, D.; Aba, D.; Hearne, S.; Crossa, J.; Gedil, M. Genetic gains in grain yield of a maize population improved through marker-assisted recurrent selection under stress and non-stress conditions in West Africa. Front. Plant Sci. 2017, 8, 841. [CrossRef]

23. Bankole, F.; Menkir, A.; Olaoye, G.; Crossa, J.; Hearne, S.; Unachukwu, N.; Gedil, M. Genetic gains in yield and yield related traits under drought stress and favourable environments in a maize population improved using marker-assisted recurrent selection. Front. Plant Sci. 2017, 1-10. [CrossRef]

24. Crosbie, T.M.; Eathington, S.R.; Johnson, G.R.; Edwards, M.; Reiter, R.; Stark, S.; Mohanty, R.G.; Oyervides, M.; Buehler, R.E.; Walker, A.K.; et al. Plant breeding: Past, present, and future. In Plant Breeding: The Arnel R. Hallauer International Symposium; Lamkey, K.R., Lee, M., Eds.; Blackwell Publishing: Ames, IA, USA, 2006; pp. 3-50.

25. Astatke, D.K. Genetic Gain in Provitamin A and Genetic Diversity Changes of Two Synthetic Maize Populations Improved Through Marker Assisted Recurrent Selection. Master's Thesis, University of Ibadan, Ibadan, Nigeria, 2018.

26. Senete, C.T.; Guimarães, P.E.D.O.; Paes, M.C.D.; De Souza, J.C. Diallel analysis of maize inbred lines for carotenoids and grain yield. Euphytica 2011, 182, 395-404. [CrossRef]

27. Suwarno, W.B.; Pixley, K.V.; Palacios-Rojas, N.; Kaeppler, S.M.; Babu, R. Formation of heterotic groups and understanding genetic effects in a provitamin A biofortified maize breeding program. Crop Sci. 2014, 54, 14-24. [CrossRef]

28. Muthusamy, V.; Hossain, F.; Thirunavukkarasu, N.; Saha, S.; Agrawal, P.K.; Gupta, H.S. Genetic analyses of kernel carotenoids in novel maize genotypes possessing rare allele of $\beta$-carotene hydroxylase gene. Cereal Res. Commun. 2016, 44, 669-680. [CrossRef]

29. Oben-Bio, E.; Badu-Apraku, B.; Ifie, B.E.; Danquah, A.; Blay, E.T.; Annor, B. Genetic analysis of grain yield and agronomic traits of early provitamin A quality protein maize inbred lines in contrasting environments. J. Agric. Sci. 2019, 157, 413-433. [CrossRef] 
30. Egesel, C.O.; Wong, J.C.; Lambert, R.J.; Rocheford, T.R. Combining ability of maize inbreds for carotenoids and tocopherols. Crop Sci. 2003, 43, 818-823. [CrossRef]

31. Halilu, A.D.; Ado, G.; Aba, D.A.; Usman, S.I. Genetics of carotenoids for provitmain A biofortification in tropical-adapted maize. Crop J. 2016, 4, 313-322. [CrossRef]

32. Hallauer, A.R.; Filho, J.B.M.; Carena, M.J. Heterosis. In Quantitative Genetics in Maize Breeding; Prohens, J., Nuez, F., Carena, M.J., Eds.; Springer: New York, NY, USA, 2010; pp. 477-481.

33. Burt, A.J.; Grainger, C.M.; Shelp, B.J.; Lee, E.A. Heterosis for carotenoid concentration and profile in maize hybrids. Genome 2011, 1004, 993-1004. [CrossRef] [PubMed]

34. National Agricultural Seeds Council of Nigeria. 2017 Annual Report; NASC: Abuja, Nigeria, 2017; 54p.

35. Kamara, A.Y.; Kamai, L.O.; Omoigui, A.; Togola, A.; Ekeleme, F.; Onyibe, J.E. Guide to Maize Production in Northern Nigeria; International Institute of Tropical Agriculture: Ibadan, Nigeria, 2020; 18p.

36. Howe, J.A.; Tanumihardjo, S.A. Carotenoid-biofortified maize maintains adequate vitamin A status in Mongolian gerbils. J. Nutr. 2006, 136, 2562-2567. [CrossRef] [PubMed]

37. Galicia, L.; Miranda, A.; Gutierrez, M.G.; Custodio, O.; Rosales, A.; Ruiz, N.; Surles, R.; Palacios, N. Laboratory of Nutritional Quality of Corn and Analysis of Plant Tissue: Laboratory Protocols 2012. Determination of Carotenoids in Corn by Liquid Chromatography; CIMMYT: Mexico City, Mexico, 2012; pp. 1-58.

38. US Institute of Medicine. Dietary Reference Intakes for Vitamin A, Vitamin K, Arsenic, Boron, Chromium, Copper, Iodine, Iron, Manganese, Molybdenum, Nickel, Silicon, Vanadium, and Zinc; The National Academies Press: Washington, DC, USA, 2001.

39. SAS Institute. SAS System for Windows; Release 9.4; SAS Institute Inc.: Cary, NC, USA, 2012.

40. Menkir, A.; Kling, G. Response to recurrent selection for resistance to Striga hermonthica (Del.) Benth in a tropical maize population. Crop Sci. 2007, 47, 674-683. [CrossRef]

41. Zhang, Y.; Kang, M.S.; Lamkey, R.K. DIALLEL-SAS05: A comprehensive program for Griffing's and Gardner-Eberhart analyses. Agron. J. 2005, 97, 1097-1106. [CrossRef]

42. Rodríguez, F.; Alvarado, G.; Pacheco, Á.; Crossa, J.; Burgueño, J. AGR-R (Analysis of Genetic Designs in R); Version 5.0; International Maize and Wheat Improvement Center (CIMMYT): Mexico City, Mexico, 2018.

43. Baker, R.J. Issues in diallel analysis. Crop Sci. 1978, 18, 535-536. [CrossRef]

44. Falconer, D.S.; Mackay, T.F.C. Introduction to Quantitative Genetics, 4th ed.; Longman Group: Edinburgh, UK, 1996.

45. Kutka, F. Open-pollinated vs. Hybrid maize cultivars. Sustainability 2011, 3, 1531-1554. [CrossRef]

46. Vales, M.I.; Malvar, R.A.; Revilla, P.; Ordas, A. Recurrent selection for grain yield in two Spanish maize synthetics populations. Crop Sci. 2001, 41, 15-19. [CrossRef]

47. Dudley, J.W.; Lambert, R.J. 100 generations of selection for oil and protein in corn. Plant Breed. Rev. 2004, 24, 79-110.

48. Ortiz-Covarrubias, Y.; Dhliwayo, T.; Palacios-Rojas, N.; Ndhlela, T.; Magoroskosho, C.; Aguilar-Rincon, V.H.; Cruz-Morales, A.; Trachsel, S. Effects of drought and low nitrogen stress on provitamin A carotenoid content of biofortified maize hybrids. Crop Sci. 2019, 59, 2521-2532. [CrossRef]

49. Li, R.; Xiao, L.; Wang, J.; Lu, Y.; Rong, T.; Pan, G.; Wu, Y.; Tang, Q.; Lan, H.; Cao, M. Combining ability and parent-offspring correlation of maize (Zea mays L.) grain $\beta$-carotene content with a complete diallel. J. Integr. Agric. 2013, 12, 19-26. [CrossRef]

50. Menkir, A.; Maziya-Dixon, B.; Mengesha, W.; Rocheford, T.; Alamu, E.O. Accruing genetic gain in pro-vitamin A enrichment from harnessing diverse maize germplasm. Euphytica 2017, 213, 105-116. [CrossRef]

51. Badu-Apraku, B.; Annor, B.; Oyekunle, M.; Akinwale, R.; Fakorede, M.; Talabi, A.; Akaogu, I.; Melaku, G.; Fasanmade, Y. Grouping of early maturing quality protein maize inbreds based on SNP markers and combining ability under multiple environments. Field Crops Res. 2015, 183, 169-183. [CrossRef]

52. Derera, J.; Tongoona, P.; Vivek, S.B.; Lang, M.D. Gene action controlling grain yield and secondary traits in southern African maize hybrids under drought and non-drought environments. Euphytica 2008, 162, 411-422. [CrossRef]

53. Maqbool, M.A.; Aslam, M.; Beshir, A.; Khan, M.S. Breeding for provitamin A biofortification of maize (Zea mays L.). Plant Breed. 2018, 137, 451-469. [CrossRef]

54. Birchler, J.A.; Auger, D.L.; Riddle, N.C. In search of the molecular basis of heterosis. Plant Cell 2003, 15, 2236-2239. [CrossRef] 
55. Messias, R.; Galli, V.; Silva, S.; Rombaldi, C.V. Carotenoid biosynthetic and catabolic pathways: Gene expression and carotenoid content in grains of maize landraces. Nutrients 2014, 6, 546-563. [CrossRef]

56. Menkir, A.; Mazia-Dixon, B. Influence of genotype and environment on $\beta$-carotene content of tropical yellow-endosperm maize genotypes. Maydica 2004, 49, 313-318.

Publisher's Note: MDPI stays neutral with regard to jurisdictional claims in published maps and institutional affiliations.

(C) 2020 by the authors. Licensee MDPI, Basel, Switzerland. This article is an open access article distributed under the terms and conditions of the Creative Commons Attribution (CC BY) license (http://creativecommons.org/licenses/by/4.0/). 